\title{
Effect of Microstructure on HTPB Based Polyurethane (HTPB-PU)
}

\author{
Abhijit Dey $^{1 *}$, Md Abdul Shafeeuulla Khan ${ }^{1}$, Javaid Athar ${ }^{1}$, Arun Kanti Sikder ${ }^{1}$ and Santanu Chattopadhyay ${ }^{2}$ \\ 1. Energetic Materials Research Division, High Energy Materials Research Laboratory, Sutarwadi, Pune 411021, India \\ 2. Rubber Technology Centre, Indian Institute of Technology, Kharagpur, West Bengal 721302, India
}

\begin{abstract}
Effect of HTPB (Hydroxy-terminated polybutadiene) microstructure on HTPB-PU (HTPB based polyurethane network) were investigated. These evaluations were carried out by mean of several characterization like measurement of gel point, mechanical properties, hardness, cross link density measurement and thermal analysis like STA (TG-DTA). The results showed that polyurethane synthesized from HTPB prepolymer containing higher amount of cis and trans microstructure i.e. Grade II exhibited better pot life, good mechanical properties and thermal stability with higher cross link density.
\end{abstract}

Key words: Microstructure, polyurethane, hydroxyl terminated polybutadiene, propellant, cross link density.

\section{Introduction}

In the 1960s, HTPB (Hydroxy-terminated polybutadiene) was developed and its first test in rocket motors had been conducted in 1972 which showed advantages over CTPB (Carboxyl-terminated polybutadiene) [1]. HTPB has since become the most widely used state-of-art composite propellant binder with excellent mechanical and increased IM (Insensitive munitions) properties. Several commercially available explosives are used with the HTPB in propellant formulation [2]. HTPB has also been used for various other applications. HTPB based polyurethanes have been studied by several authors for the separation of organic compounds for selective adsorption of proteins and for selective gas transport properties [3-5]. HTPB has also been successfully used for the fabrication of elastic conducting polymer micro-particles with core-shell structure [6]. Several authors have studied the shock response behaviors of the HTPB polyurethane with and without energetic materials [7-9]. The excellent shock absorbing capacity of the HTPB polyurethane drastically reduces

*Corresponding author: Shri Abhijit Dey, Assistant Director/Scientist 'D', research field: energetic material. E mail: abhidey_bkn@yahoo.com the sensitivity and vulnerability of the explosive materials.

In recent time, an immense attention has been given to improve the mechanical properties of HTPB-PU (HTPB based polyurethane) [10-17]. For example, Wingborg et al. [18]. had used diol as chain extender and different diisocyanate as curing agent and investigated its impacts on mechanical properties. They achieved highest tensile strength with Desmodur-W (H12MDI) and 1, 4- BDO (Butane diol). Tao [19] have modified the HTPB-PU by introducing PTMG (Polytetrahydrofuran glycol) into the PU backbone. Chen [20] and Okamoto [21] had studied mechanical properties of HTPB-PU blend with other polymer. Some scientists [12, 22-24] had put their attention on IPNs (interpenetrating polymer networks) technology to improve mechanical properties of HTPB-PU. So far, most of published works on HTPB-PU based IPNs had been focused on linear one-dimensional polymers, such as poly-methyl methacrylate [10], poly-methacrylic acid B ester [11], polystyrene [12], Poly-(ethylene oxide) [22] and polyethylene glycol [23].

To improve the HTPB-PU properties, microstructure i.e. cis, trans and vinyl of HTPB also 
plays a vital role. The flow characteristics of the HTPB and the mechanical properties of the corresponding polyurethane depend upon the concentration ratio of microstructures present in the sample. Though it looks like a simple molecule but its structure is really complex. HTPB has three different types of microstructures and their relative percentage of microstructure in a given sample depends upon the polymerization condition by which it was synthesized. The three possible configurations of microstructures are: (a) cis configuration (Fig. 1a) where both the $\mathrm{CH}_{2}$ groups are on the same side of the double bond and become close to each other, (b) trans configuration (Fig. 1b) where they are on the opposite sides and quite apart and (c) 1, 2 vinyl configuration (Fig. 1c) which again leads three types of isomerism viz. isotactic (Fig. 2a), syndiotactic (Fig. 2b) and atactic (Fig. 2c). It has a double bond in each repeated unit $-\left(\mathrm{CH}_{2}-\mathrm{CH}=\mathrm{CH}-\mathrm{CH}_{2}\right)_{\mathrm{n}}-$. The viscosity of the HTPB prepolymer increases with increase in vinyl content. The mechanical properties such as tensile strength, percentage elongation of the corresponding polyurethane show significant improvement with increasing cis, trans content and decreasing vinyl content $[25,26]$. Each of these double bonds provides a site for a steric isomerism, depending on whether the
$\mathrm{CH}_{2}$ groups attached to the carbon atoms on either side of the double bond are close to or away from each other.

In practice however, polymerization to $100 \%$ cis or $100 \%$ trans is extremely difficult and usually obtain, mixture of 1, 4-cis, 1, 4-trans and 1, 2-vinyl configurations, randomly distributed throughout the chain length.

An ideal HTPB should have trans: cis: vinyl in the ratio 55:25:20. As a rule of thumb, increasing the trans content generally increases the tensile strength of the cured polymer, increasing the cis content normally increase the elongation and increased vinyl content leads to increase in viscosity of uncured polymer matrix because the presence of pendant vinyl group acts as a anchor and prevents the molecular slippage i.e. flow is restricted. Moreover, if a polymer contains more vinyl group, more prone to ageing (hardening) during storage, because a possible cross linking may occur between vinyl group and nearby double bond.

The objective of this paper is to study the effect of microstructures on various properties of HTPB-PU by means of rheology, crosslink density, hardness, mechanical properties and STA (simultaneous thermal analysis). Table 1 shows the polyurethane composition with different grades of HTPB.

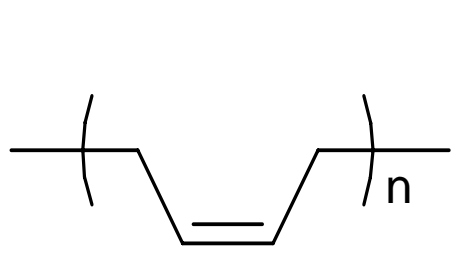

(a)

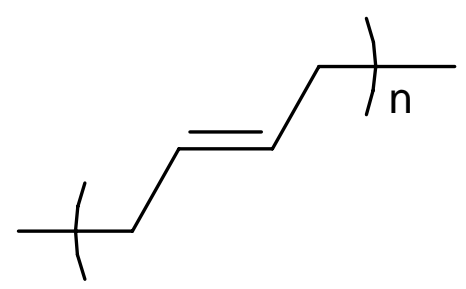

(b)

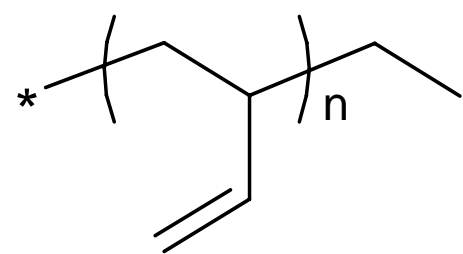

(c)

Fig. 1 Microstructure of HTPB: (a) cis, (b) trans and (c) vinyl.

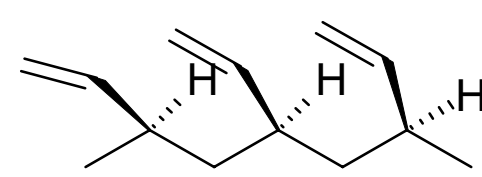

(a)

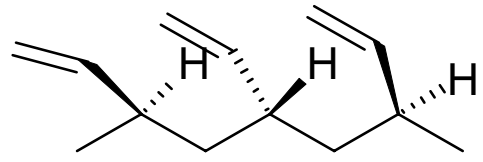

(b)

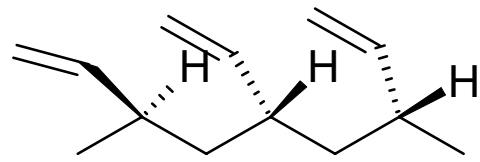

(c)

Fig. 2 Configuration of HTPB: (a) isotactic, (b) syndiotactic and (c) atactic. 
Table 1 Polyurethane composition.

\begin{tabular}{lllll}
\hline Sl. No & Ingredients & $\begin{array}{l}\text { HTPB (Gr. I)-PU } \\
(\mathrm{phr})\end{array}$ & $\begin{array}{l}\text { HTPB (Gr. II)-PU } \\
(\mathrm{phr})\end{array}$ & $\begin{array}{l}\text { HTPB (Gr. III)-PU } \\
(\mathrm{phr})\end{array}$ \\
\hline & & 100 & 100 & 100 \\
1 & HTPB (Hydroxyl terminated polybutadiene) & 43 & 43 & 43 \\
2 & Di-octyl adipate (DOA) & 0.63 & 0.63 & 0.63 \\
3 & Pyrogallol (20 $\mu \mathrm{m})$ & 1.07 & 1.07 & 1.07 \\
4 & Adduct (n-Butane diol: trimethylol propane is 2:1) & 9.93 & 10.12 & 10.27 \\
5 & HMDI (Hexamethylene diisocyanate) & 0.15 & 0.15 & 0.15 \\
6 & DBTDL (Dibutyl tin dilaurate), NCO/OH ratio & $1: 1$ & $1: 1$ & $1: 1$ \\
\hline
\end{tabular}

\section{Experiments}

\subsection{Materials}

Three different Grades of HTPB (I, II, III) containing different concentration of microstructures (viz. cis, trans, vinyl) were used. The binder consists hydroxyl terminated polybutadiene (HTPB, purity: 99\%, $\mathrm{OH}$ value: 40-50, moisture content: $0.15 \%$ ) cured with HMDI (Hexamethyl diisocyanate, purity: $99 \%$, RI at $20^{\circ} \mathrm{C}$ : 1.4525 with $589 \mathrm{~nm}$ from Bayers) maintaining $\mathrm{NCO} / \mathrm{OH}$ ratio 1:1. Dioctyl adipate (DOA, ester content: $99 \%$, saponification value: $303 \pm 3$, moisture content: $0.5 \%$ from Subhas chemical) was used as a plasticizer to increase processability. The additive pyrogallol (melting point:131 to $134{ }^{\circ} \mathrm{C}$, from S. D. Fine chemical) was used as a cross linker. The mixture of trimethylol propane $(\mathrm{OH}$ value-1220, moisture content: $0.5 \%$ from Celenese) and n-butane diol $\left(\mathrm{OH}\right.$ value-1220, RI at $30{ }^{\circ} \mathrm{C}: 1.444+0.002$, moisture content: $0.5 \%$, from Biaf) was used as an adduct in the composition. Dibutyl tin dilaurate (DBTL, from S. D. fine) was used as curing catalyst.

\subsection{Processing}

Polyurethane formulation was mixed in $700 \mathrm{~g}$ batch level using a vertical planetary mixer of 1 lit capacity. All batches were mixed and cast under vacuum by slurry cast techniques [27]. The polymer was cured at $60{ }^{\circ} \mathrm{C}$ for 2-4 days in a water-jacketed oven. The polymer compositions comprised of three different HTPB. The polymers were subjected to various performance tests.

\subsection{Characterization}

Rheometer (Model-Stresstech Make-Rheologica instrument $\mathrm{AB}$, Sweden) was used to study the gelpoint and curing behaviour. The curing profile of different grades of HTPB with hexamethylene diisocyanate curing agent were recorded by the rheometer to locate the gel point during curing reaction.

Tensile specimens were punched out from the sheets. The tests were carried out as per the ASTM D-638 method in a universal testing machine (UTM, Model: Hountsfield H25KS, UK). Specimen is held between two separate anchoring positions, which are given relative motion with respect to each other. Force at anchor point against their displacement is poltted and various mechanical properties like tensile strength, modulus and elongation are calculated. Tensile properties reported here were the averages of five samples. The test was conducted on the UTM at a rate of crosshead movement of $50 \mathrm{~mm} / \mathrm{min}$.

Hardness of the specimens were carried out as per the ASTM D-2240 method in Hardness tester shore D (Ranges: 0 to 100 D Nos, Indenter: Sharp cone, Graduation: 1 shore DNos, Check gauge: 50 hore D Nos).

Crosslink density [28] was measured by swelling experiments. These experiments were conducted on small rectangular (approximately $20 \times 10 \times 2 \mathrm{~mm}$ ) specimens of the synthesized PU's in toluene at room temperature for one week. A swelling time of one week was chosen as the basis of the test results on several samples which showed no significant changes after one week of immersion in toluene. At the end of 
the immersion period, the sample was removed, rapidly blotted with tissue and transferred to the weighing bottle to obtain the swollen weight of the sample. The crosslink density was calculated, based on the values of $\mathrm{Vr}$ and $\mathrm{V}$. obtained, using equation:

Crosslink density, network chain per gram

$$
\begin{gathered}
=-\left[\ln (1-\mathrm{Vp})+(\mathrm{Vp})+\mathrm{X}(\mathrm{Vp})^{2}\right] /\left\{\mathrm { Dp } ( \mathrm { Vo } ) \left[(\mathrm{Vr})^{1 / 3}-\right.\right. \\
(\mathrm{Vp}) / 2]\},
\end{gathered}
$$

where, $\mathrm{Vp}=1 /(1+\mathrm{Q}), \mathrm{Q}$ is the ratio of the weight of solvent in the swollen polymer $(\mathrm{X} \cdot \mathrm{Dp})$ and the Weight of polymer (X-Do). Here $\mathrm{Vp}$ is volume fraction of polymer in the swollen polymer, $\mathrm{X}$ is huggins polymer-solvent interaction constant, $\mathrm{Dp}$ is density of polymer $\left(\mathrm{g} / \mathrm{cm}^{3}\right)$, Vo is molar volume of solvent $\left(\mathrm{cm}^{3} / \mathrm{mol}\right)$ and Do is density of solvent $\left(\mathrm{g} / \mathrm{cm}^{3}\right)$.

Simultaneous thermogravimetric analyser (STA, Model no: SDTQ 660, Make: TA instruments, USA) was used to measure the heat flow and weight changes associated with the phase/physical state transitions and endothermic decomposition of materials over the temperature range. The test has been carried out between ambient to $1,000{ }^{\circ} \mathrm{C}$ with a heating rate of $20{ }^{\circ} \mathrm{C} /$ min was chosen.

\section{Results and Discussion}

Polyurethane reaction is very sensitive to moisture. Diisocyanate or triisocyanate can reacts with moisture rapidly. Hence the effective curative concentration for curing reaction becomes lower. This would result inferior mechanical property. Thus, an exhaustive analysis of the raw materials must be carried out before preceding further.

The curing profiles were studied with different grade of HTPB with HMDI. The corresponding graphical representations were given in Fig. 3. According to the curing profile, it was found that sample (b) i.e. HTPB Gr. 2 + HMDI having higher gel point (approx. $93 \mathrm{~min}$ ) compare to the other two composition. It indicates that HTPB Gr. 2 have higher potlife due to less vinyl content and lower molecular weight distribution. In presence of vinyl microstructure and broad molecular weight distribution, cross linking reaction occur at much faster rate, hence gel point time decreases. In HTPB Gr. 1 (approx. $86 \mathrm{~min}$ ) vinyl content is very high and molecular weight distribution is broad, hence gel point should be the lowest. Experimental finding supports the above explanation regarding the gel point. In HTPB Gr. 3 gel time was found to be intermediate value (approx. $80 \mathrm{~min}$ )

In Table 2, Different polyurethane sheets show variation in tensile strength, elongation. HTPB (Gr. 2)-PU sample shows remarkable higher mechanical

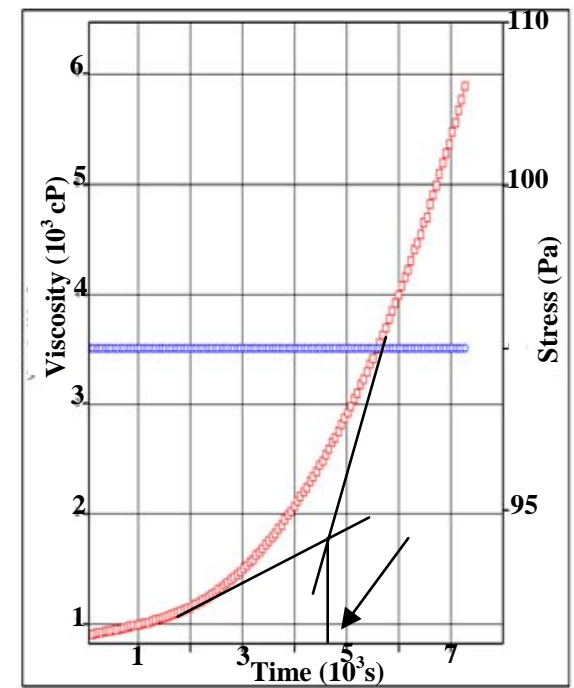

(a)

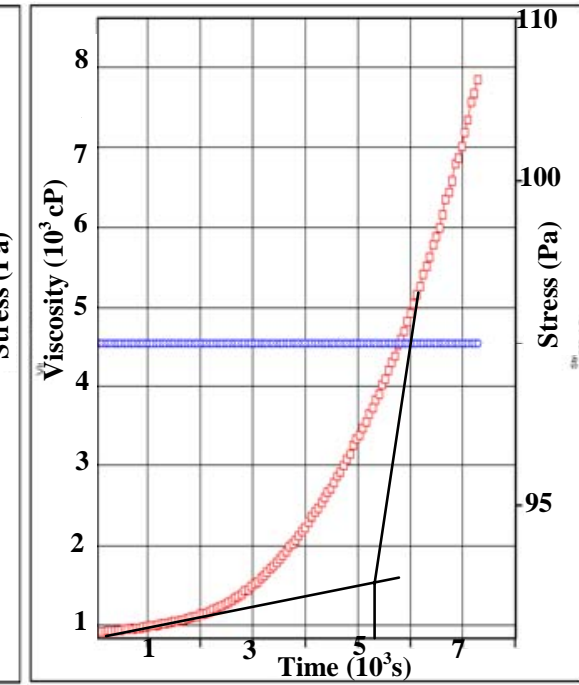

(b)

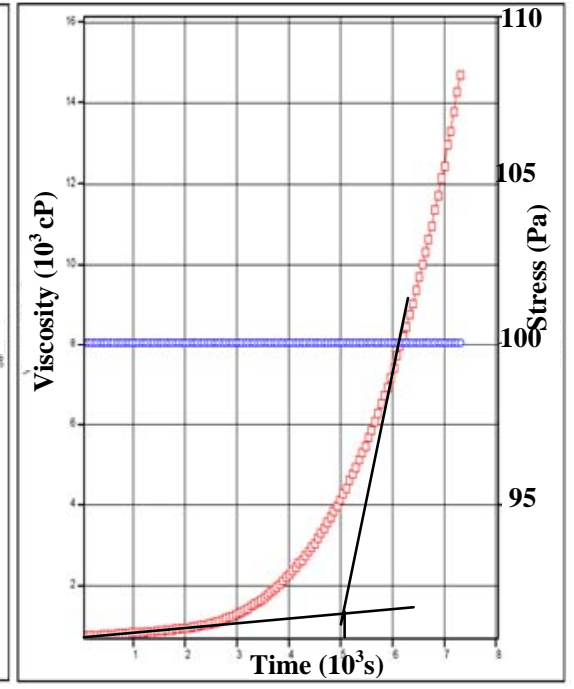

(c)

Fig. 3 Curing profile study of (a) HTPB Gr. 1 + HMDI, (b) HTPB Gr. 2 + HMDI and (c) HTPB Gr. 1 + HMDI. 
Table 2 Mechanical properties of HTPB matrix.

\begin{tabular}{lllll}
\hline Sl. No. & Mechanical properties & HTPB (Gr. 1)-PU & HTPB (Gr. 2)-PU & HTPB (Gr. 3)-PU \\
\hline 1. & Tensile strength $\left(\mathrm{kg} / \mathrm{cm}^{2}\right)$ & 3.52 & 4.64 & 4.46 \\
2. & Elongation @ Fmax (\%) & 83.2 & 104.56 & 50.82 \\
3. & Elongation @ Break (\%) & 83.39 & 104.7 & 50.94 \\
\hline
\end{tabular}

HTPB (Gr. 1)-PU: polyurethane sample from HTPB (Gr. 1), HTPB (Gr. 2)-PU: polyurethane sample from HTPB (Gr. 2), HTPB (Gr. 3)-PU: polyurethane sample from HTPB (Gr. 3).

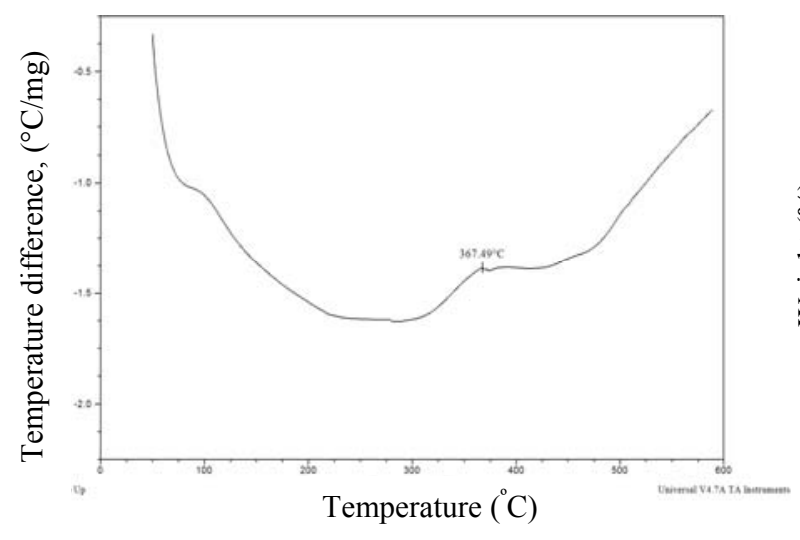

(a)

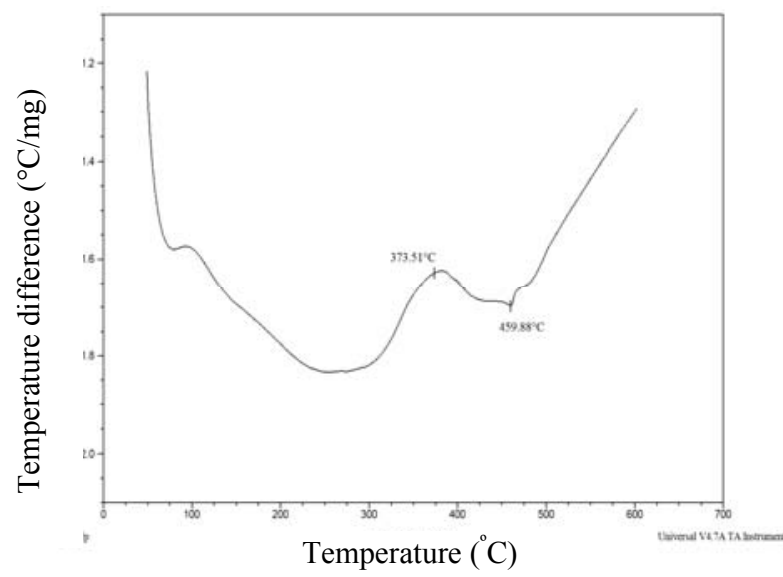

(c)

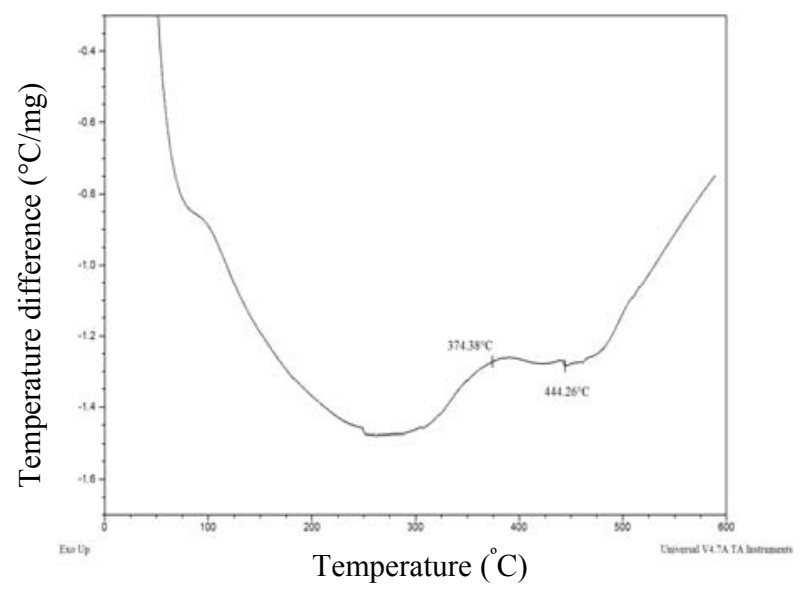

(e)

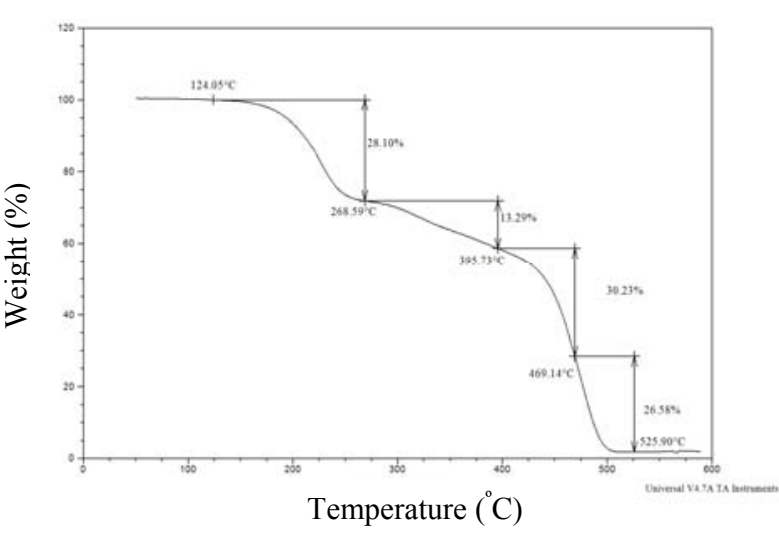

(b)

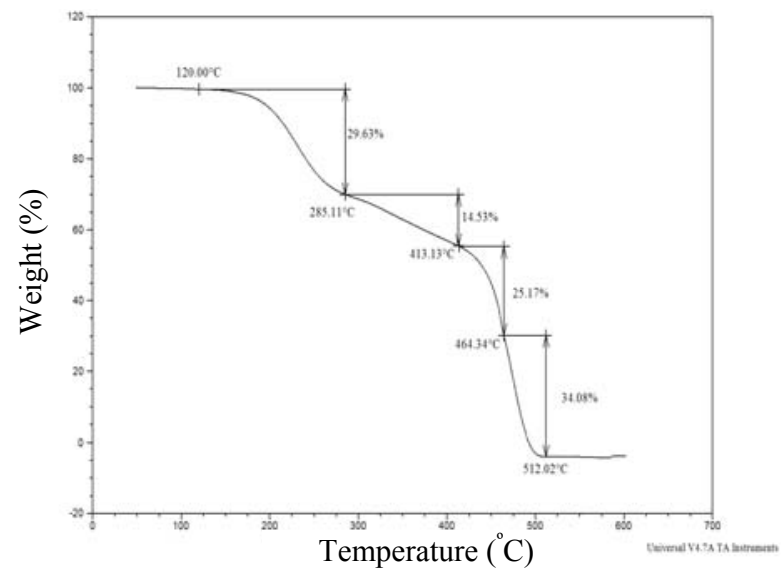

(d)

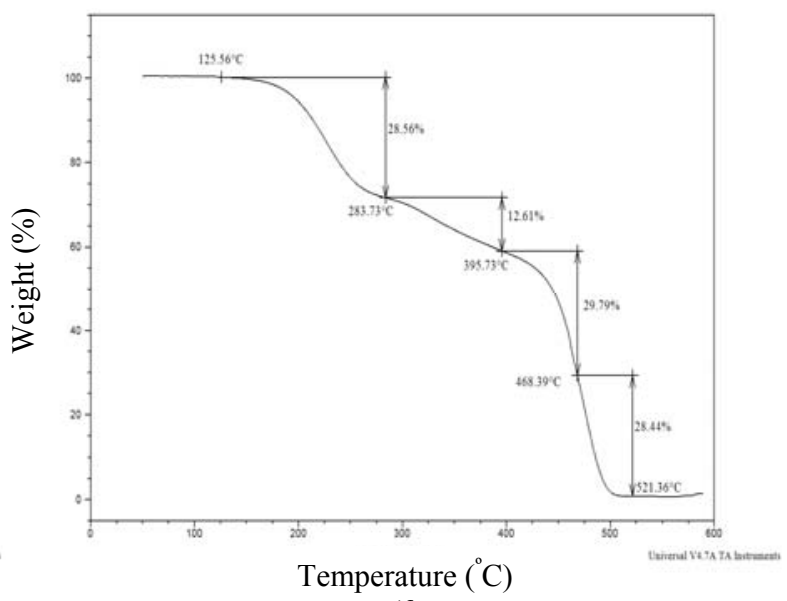

(f)

Fig. 4 (a), (c) and (e) represent DTA traces, (b), (d) and (f) represent TGA traces of HTPB (Gr. 1)-PU, HTPB (Gr. 2)-PU and HTPB (Gr. 3)-PU, respectively. 
Table 3 DTA traces of polyurethane sheet.

\begin{tabular}{lllll}
\hline No & Properties & HTPB (Gr. 1)-PU & HTPB (Gr. 2)-PU & HTPB (Gr. 3)-PU \\
\hline 1 & Exotherm $\left({ }^{\circ} \mathrm{C}\right)$ & 367.5 & 373.5 & 374.4 \\
2 & Endotherm $\left({ }^{\circ} \mathrm{C}\right)$ & ----- & 459.9 & 444.3 \\
\hline
\end{tabular}

HTPB (Gr. 1)-PU: polyurethane sample from HTPB (Gr. 1), HTPB (Gr. 2)-PU: polyurethane sample from HTPB (Gr. 2), HTPB (Gr. 3)-PU: polyurethane sample from HTPB (Gr. 3).

Table 4 TGA traces of polyurethane sheet.

\begin{tabular}{lllll}
\hline No & $\begin{array}{l}\text { Properties } \\
\left.\text { wt. loss \% (Temp. range }\left({ }^{\circ} \mathrm{C}\right)\right)\end{array}$ & HTPB (Gr. 1)-PU & HTPB (Gr. 2)-PU & HTPB (Gr. 3)-PU \\
\hline 1 & $1^{\text {st }}$ stage & $28.1(124-268.6)$ & $29.6(120-285.1)$ & $28.6(125.6-283.6)$ \\
2 & $2^{\text {nd }}$ stage & $13.3(268.6-395.7)$ & $14.5(285.1-413.1)$ & $12.61(283.7-395.7)$ \\
3 & $3^{\text {rd }}$ stage & $30.2(395.7-469.1)$ & $25.2(413.1-464.3)$ & $29.8(395.7-468.4)$ \\
4 & $4^{\text {th }}$ stage & $26.6(469.1-525.9)$ & $34.1(464.3-512)$ & $28.4(468.4-521.4)$ \\
\hline
\end{tabular}

HTPB (Gr. 1)-PU: polyurethane sample from HTPB (Gr. 1), HTPB (Gr. 2)-PU: polyurethane sample from HTPB (Gr. 2), HTPB (Gr. 3)-PU: polyurethane sample from HTPB (Gr. 3).

Table 5 Cross link density measurement.

\begin{tabular}{lllllll}
\hline Sl. No & Sample & Sample weight $(\mathrm{g})$ & Swollen weight $(\mathrm{g})$ & $\mathrm{Vr}$ & volume swollen (\%) & Cross link density \\
\hline 1 & HTPB(Gr. 1)PU & 0.564 & 2.64 & 0.2038 & 330 & $2.07 \times 10^{-1}$ \\
2 & HTPB(Gr. 2)PU & 0.626 & 3.44 & 0.1733 & 478 & $1.512 \times 10^{-1}$ \\
3 & HTPB(Gr. 3)PU & 0.676 & 2.78 & 0.2135 & 390 & $2.693 \times 10^{-1}$ \\
\hline
\end{tabular}

HTPB (Gr. 1)-PU: polyurethane sample from HTPB (Gr. 1), HTPB (Gr. 2)-PU: polyurethane sample from HTPB (Gr. 2), HTPB (Gr. 3)-PU: polyurethane sample from HTPB (Gr. 3).

properties i.e. tensile strength $(4.64 \mathrm{ksc})$, elongation (104.5\%) compare to other two samples. The outcome of this result depicts that mechanical properties of the end product are dependent on the microstructure concentration ratio of HTPB.

Fig. 4a, c, and e show DTA graphs of different HTPB-PU samples. The corresponding traces are given in Table 3. Different PU samples show comparable exotherm temperature but HTPB (Gr. 2)-PU shows higher endotherm temperature compare to other two samples indicates higher stability of HTPB (Gr. 2)-PU.

Fig. $4 b, d$ and $f$ depict TGA graphs of various PU sample. The corresponding data were highlighted in Table 4. HTPB (Gr. 2)-PU shows higher weight loss at the last stage compare to other samples, these indicate better stability at high temperature. This result supports DTA results.

The crosslink density measurement results were given in Table 5. The results show comparable cross link densities of three sample $\left(1.5 \times 10^{-1} \sim 3 \times 10^{-1}\right)$. HTPB (Gr. 2)-PU shows relatively lower crosslink density compare to other two samples due to presence of higher cis, trans microstructure compare to vinyl. With increase of vinyl concentration, number of crosslinks increase drastically.

\section{Conclusions}

The various techniques like gel point measurement, mechanical properties, hardness, crosslink density measurement and STA (TGA-DTA) were used in this investigation lead to conclude the effect of microstructure on HTPB based polyurethane network. Different grades HTPB have different concentration of microstructure (cis, trans and vinyl). The remarkable variation in PU properties were also observed with respect to mechanical properties, thermal properties and crosslink density. НTPB (Gr. 2)-PU shows improved mechanical properties with better thermal stability and crosslink density compared to other two samples. Hence, HTPB (Gr. 2) is relatively superior as HTPB prepolymer for HTPB-PU network than the other two samples of HTPB prepolymer. 


\section{Acknowledgments}

The authors are thankful to Shri B. Bhattacharya, OS \& Director, HEMRL, Pune, India for valuable suggestions, constant encouragement and permission to publish this work.

\section{References}

[1] Daniel, M. A. 2006. "Polyurethane Binder Systems for Polymer Bonded Explosives." Weapons Systems Division DSTO Defence Science and Technology Organisation.

[2] Mathieu, J., and Stucki, H. 2004. Military high explosive, Chimia. International Journal for Chemistry 58: 383-9.

[3] Gupta, T., Pradhan, N. C. and Adhikari, B. 2002. "Synthesis and Performance of a Novel Polyurethaneurea as Pervaporation Membrane for the Selective Removal of Phenol from Industrial Waste Water." Bull Material Science 25: 533-6.

[4] Yang, J. M. and Lin, H. T. 2001. "Wettability and Protein Adsorption on HTPB-Based Polyurethane Films." Journal of Membrane Science 187: 159-69.

[5] Chen, S. H., Yu, K. C., Houng, S. L. and Lai, J. Y.2000 "Gas Transport Properties of HTPB Based Polyurethane." Journal of Membrane Science 173 (1):99-106.

[6] Kuo, C., Samuelson, L. A., McCarthy, S. P., Tripathy, S .K. and Kumar, J. 2003. "Polybutadiene Modified Polyaniline Microparticles.” J Macromolecular Science. Part A. Pure Applied Chemistry A 40: 1383-96.

[7] Bohn, M. A. and Elsner, P. 1999. "Aging of the Binders GAP-N100 and HTPB-IPDI Investigated by Torsion-DMA." Propellants, Explosives, Pyrotechnics 24: 199-205.

[8] Millett, J. C. F., Bourne, N. K. and Akhavan, J. 2004. "The Response of Hydroxy-Terminated Polybutadiene to One-Dimensional Shock Loading." Journal of Applied Physics 95: 4722-7.

[9] Millett, J. C. F. and Bourne, N. K. 2004. "The Shock Induced Equation of State of Three Simple Polymers." Journal of Physics D: Applied Physics. 37: 2901-7.

[10] Wang, S. H., Zawadzki, S. and Akcelrud, L, 2000. "HTPB-Based Polyurethanes. II. SINs with PMMA." . Journal of Polymer Science: Part B: Polymer Physics 38 (22): 2861-72.

[11] Zhang, L., Fan, X. P. and Tan, H. M. 2006. "Study on HTPB Based PU/PIMA Interpenetrating Polymer Networks." Fine Chemical. 23 (10): 1019-1023.

[12] Parthiban, S., Raghunanadan, B. N. and Jian, S. R. 1992. "Interpenetrating Polymer Networks as Binders for Solid Composite Propellants." Defence Science Journal 42 (3): 147-56.

[13] Voit, B1. 2003. "Hyperbranched Polymers: a Chance and a Challenge.” Comptes Rendus Chimie 6 (8-11): 821-832.

[14] Mitsutoshi, J. and Masa-aki, K. 2001. "Hyperbranched Polymers: a Promising New Class of Materials." Progress in Polymer Science 26 (8): 1233-58.

[15] Yates, C. R. and Hayes, W. 2004. "Synthesis and Applications of Hyperbranched Polymers." European Polymer Journal. 40 (7): 1257-81.

[16] Gao, C. and Yan, D. Y. 2004. "Hyperbranched Polymers: from Synthesis to Applications." Progress in Polymer Science 29 (3): 183-275.

[17] Malmstroém, E., Johansson, M. and Hult, A. 1998. "Effect of Core-Forming Molecules on Molecular Weight Distribution and Degree of Branching in the Synthesis of Hyperbranched Polymers." Macromolecules 31 (2): 239-248.

[18] Wingborg, N. 2002. "Increasing the Tensile Strength of HTPB with Different Isocyanates and Chain Extenders." Polymer Testing 21 (3): 283-7.

[19] Tao, H., Liu, X. and Ma, T. 2011. "Preparation and Mechanical Properties of Polyurethane Elastomer with Two Soft Segments of HTPB/PTMG." Advanced Materials Research 150-151: 1689-92

[20] Chen, C. J., Tseng, H., Lu, H. T., Tseng, W. Y. and Tsai, M. H. "Thermal and Tensile Properties of HTPB-Based PU with PVC Blends." Materials Science and Engineering A 528 (15): 4917-23.

[21] Okamoto, K., Kohga, M. and Hasue, K. 2009. "Thermal Behavior and Tensile Property of PTHF/HTPB Blend." Science and Technology of Energetic Materials 70 (3-4): 87-93.

[22] Plesse, C., Vidal, F., Gauthier, C., Pelletier, J. M., Chevrot, C. and Teyssiéa, D. 2007. "Poly (Ethylene Oxide)/Polybutadiene Based IPNs Synthesis and Characterization.” Polymer 48 (3): 696-703.

[23] Luo, Y., Miao, Y. and Xu, F. 2011. "Study on Synthesis and Properties of Novel HTPB/PEG Polyurethane." Applied Mechanics and Materials 66-68 (1): 170-3.

[24] Song, X. J., Luo, Y. J., Liu, L. Q., LI, J and Guo, K. 2010. "Mechanical Properties of Different End-Group Modified Hyperbranched Polyester/HTPB-PU IPN." New Chemical Materials 38 (4): 61-3.

[25] Manjari, R., Joseph, V. C., Pandureng, L. P. and Sriram, T. 1993. "Structure-Property Relationship of HTPB-Based Propellants. I. Effect of Hydroxyl Value of HTPB Resin." Journal Applied Polymer Science 48: 271-8.

[26] Nazare, A. N., Deuskar, V. D., Asthana, S. N. and Shrotri, P. G. 1993. "Influence of Charecteristics of HTPB on Mechanical Properties Ballistic Behavior of Composite Propellant.' Journal of Polymer Material 10: 213.

[27] Gould, R. F. 1969. "Propellant Manufacture, Hazards and Testing, Advances in Chemistry No 88." Americal chemical Society, Washington DC.

[28] BarlkanI, M. and Hepburn, C. 1992. Iranian Journal of Polymer Science \& Technology. 1 (1):1-5. 